\title{
Penaeus monodon caspase is targeted by a white spot syndrome virus anti-apoptosis protein
}

\author{
Jiann-Horng Leu ${ }^{a}$, Hao-Ching Wang ${ }^{b}$, Guang-Hsiung Kou ${ }^{a}$, Chu-Fang Lo ${ }^{a, *}$
}

\author{
anstitute of Zoology, National Taiwan University, Taipei 10617, Taiwan, ROC \\ $\mathrm{b}$ Institute of Biochemical Sciences, National Taiwan University, Taipei 10617, Taiwan, ROC
}

Received 18 May 2007; received in revised form 16 August 2007; accepted 17 August 2007 Available online 7 September 2007

KEYWORDS
Penaeus monodon;
Caspase;
Inhibitor of apoptosis
protein;
IAP;
White spot syndrome
virus;
WSSV;
Apoptosis;
WSSV449

\section{KEYWORDS}

Caspase;

Inhibitor of apoptosis

protein;

IAP;

virus;

Apoptosis;

\begin{abstract}
Caspases play a central and evolutionarily conserved role in mediating and executing apoptosis. Here, we report the cloning and characterization of a caspase from Penaeus monodon, Pm caspase. The full-length $\mathrm{Pm}$ caspase cDNA is $1386 \mathrm{bp}$, encoding a polypeptide of 304 amino acids with a calculated molecular mass of $34.3 \mathrm{kDa}$. BLASTP analysis against the NCBI nr database showed that Pm caspase is similar to insect effector caspases. RT-PCR analysis showed that Pm caspase mRNA is expressed in all examined tissues. When Pm caspase was overexpressed in SF-9 cells, the cells showed apoptotic morphological features, including the formation of apoptotic bodies and DNA ladders. The caspase- 3 activity of Pm caspase was determined using the recombinant protein purified from Escherichia coli. Both RT-PCR and qRT-PCR analyses showed that the RNA levels of Pm caspase and $P$. monodon inhibitor of apoptosis protein $(P m I A P)$ remained unchanged after white spot syndrome virus (WSSV) infection. We also used Pm caspase to show that WSSV449, an anti-apoptosis protein encoded by WSSV, is a direct caspase inhibitor. (c) 2007 Elsevier Ltd. All rights reserved.
\end{abstract}

\section{Introduction}

Apoptosis, a cell suicide program that is used to remove surplus or damaged cells, plays important roles during embryonic development and in the adult [1]. Since the first introduction of the concept of apoptosis in 1972 by Kerr et al. [2], many studies have shown that the underlying mechanisms and molecules involved are highly conserved from mammals to nematodes [3]. Among these molecules, there is a large family of cysteine proteases that play a central and evolutionarily conserved role in mediating and executing apoptosis. These cysteine proteases specifically

\footnotetext{
Abbreviations: IAP, inhibitor of apoptosis protein; WSSV, white spot syndrome virus; UTR, untranslated region.

GenBank accession number of Penaeus monodon caspase: EF114674.

*Corresponding authors. Tel.: +886223633562; fax: +886223638179 .

E-mail addresses: ghkou@ntu.edu.tw (G.-H. Kou), gracelow@ntu.edu.tw (C.-F. Lo).
} 
cleave proteins at sites that follow aspartate (Asp) residues, and they are therefore called caspases.

Caspases are the principal executioners of apoptosis, and due to their destructive nature they need to be tightly controlled. They are produced in cells as inactive zymogens, and must undergo proteolytic cleavages at internal Asp sites to become activated. The inactive caspase zymogen consists of an amino-terminal prodomain, a large subunit, and a small carboxyl-terminal subunit. After proteolytic cleavage to separate the large and small subunits, the active caspase forms a heterodimer consisting of two large and two small subunits [4].

Caspases are classified as either initiator or effector caspases. The initiators have a long prodomain (>90 amino acids) that contains specific protein-protein interaction motifs that are necessary for their activation, whereas the effectors usually have a short prodomain with only 20-30 residues. After receiving apoptotic signals, the initiator caspases are auto-activated through the assembly of a multi-component complex made up of the initiator caspases themselves and other proteins [5]. The activated initiators in turn activate the effector caspases by cleaving them at specific internal Asp residues. The activated effector caspases then cleave an array of cellular targets and destroy the cellular architecture, which ultimately results in the demise of the cells [6].

Recent studies in animal host-virus responses have shown that apoptosis plays important roles in host defense mechanisms against viral infection $[7,8]$. The apoptosis phenomenon has been well documented in shrimps infected with several viral pathogens [9-11]. The above studies showed that the characteristics of viral-induced apoptosis in shrimp are similar to those found in other animals, and that virus-induced pathogenesis in shrimps can be partly attributed to the apoptosis triggered by the virus. However, so far, only two apoptotic molecules have been identified in shrimp: a caspase gene ( $F m$ caspase) has been cloned from the shrimp Fenneropenaeus merguiensis [12] and an inhibitor of apoptosis protein (IAP) gene has also recently been cloned from Penaeus monodon in our lab [13]. The shrimp virus white spot syndrome virus (WSSV) has also been shown to encode a novel anti-apoptosis protein WSSV449 [14]. To further understand the apoptotic interplay between WSSV and the shrimp host, we therefore cloned and characterized a caspase from $P$. monodon. We further demonstrated that the apoptotic responses induced by $\mathrm{Pm}$ caspase in insect cells were completely blocked by WSSV449, and only partially blocked by PmIAP.

\section{Materials and methods}

\subsection{Cloning of Pm caspase}

A partial $P$. monodon caspase cDNA fragment was first cloned using degenerate PCR. Briefly, mRNA was isolated from $P$. monodon hepatopancreas using the QuickPrep Micro mRNA Purification Kit (GE Healthcare) according to Leu et al. [13], and $200 \mathrm{ng}$ mRNAs were primed with oligo-dTanchor primer (Roche) and reverse-transcribed with SuperScript II (Invitrogen, USA) at $42{ }^{\circ} \mathrm{C}$ for $50 \mathrm{~min}$. Following Pei et al. [15], degenerate primers, $5^{\prime}-\mathrm{CA}(\mathrm{A} / \mathrm{G}) \mathrm{GC}(\mathrm{A} / \mathrm{C} / \mathrm{G} / \mathrm{T})$
$\mathrm{TG}(\mathrm{T} / \mathrm{C}) \mathrm{CA}(\mathrm{A} / \mathrm{G}) \mathrm{GG}(\mathrm{A} / \mathrm{C} / \mathrm{G} / \mathrm{T}) \mathrm{GA}-3^{\prime}$ and $5^{\prime}$-TGCAT(A/G) $(\mathrm{A} / \mathrm{T}) \mathrm{ACCA}(\mathrm{A} / \mathrm{C} / \mathrm{G} / \mathrm{T}) \mathrm{GA} \quad(\mathrm{A} / \mathrm{C} / \mathrm{G} / \mathrm{T}) \mathrm{CC}-3^{\prime}$, were designed based on the consensus amino acid sequence of the members of the insect caspase family. PCR was performed for 40 cycles of $95^{\circ} \mathrm{C}$ for $30 \mathrm{~s}, 45^{\circ} \mathrm{C}$ for $30 \mathrm{~s}$, and $72{ }^{\circ} \mathrm{C}$ for $1 \mathrm{~min}$. Amplified fragments were cloned into the PGEM-T easy vector (Promega) and then sequenced.

$5^{\prime}$ RACE was performed using the FirstChoice ${ }^{\circledR}$ RLM-RACE kit from Ambion, Inc. according to the manufacturer's protocol. Briefly, about $200 \mathrm{ng}$ poly(A) RNA was used, and after being reverse-transcribed with random decamers, the resulting CDNA was then subjected to nested PCR using two $P m$ caspase antisense primers, 5'-AGGTATAGTGGACCAGCACTCCAG-3' and 5'-CGGCGTCGATCTCGTCCTGCTTG-3', and the two sense primers provided by the kit. For $3^{\prime}$ RACE, the cDNA synthesized from the poly(A) RNA using the oligo(dT)-anchor primer (Roche Molecular Biochemicals) was subjected to PCR using the Pm caspase sense primer, 5'-GCACGACCCTCAAGCAGGACGAG-3', and the anchor primer (Roche Molecular Biochemicals). The PCR products of both $5^{\prime}$ and 3' RACE were cloned into the pGEM-Teasy vector (Promega) and sequenced.

\subsection{Sequence analysis of Pm caspase}

The deduced amino acid sequence of Pm caspase was analyzed with BLASTP against the NCBI non-redundant (nr) database and with ScanProsite. For multiple sequence alignment and phylogenetic relationship analysis, the following insect, shrimp and vertebrate effector caspases were used: Drosophila melanogaster Dcp-1 (NP_476974.1) and Drice (NP_524551.2), Drosophila pseudoobscura caspase (Dscasp; XP_001361093), Bombyx mori caspase-1 (Bmcasp; AAN86250), Trichoplusia ni caspase-1 (Tncasp; AA017788), Helicoverpa armigera caspase-1 (Hacasp; ABS18284), Spodoptera littoralis caspase-1 (Slcasp; AA016241) Spodoptera frugiperda caspase-1 (Sfcasp; AAC47442.1), F. merguiensis caspase (Fmcasp; AY839873), Takifugu rubripes caspase-3 (Trcasp3; AAM43816), Danio rerio caspase-3 (Drcasp3; NP_571952), Gallus gallus caspase-3 (Gacasp3; NP_990056), Bos taurus caspase-3 (Btcasp3; NP_001071308), Xenopus tropicalis caspase-7 (Xecasp7; CAJ82745), Mus musculus caspase-7 (Mmcasp7; NP_031637), Rattus norvegicus caspase-7 (Rncasp7; NP_071596), and human caspase-3 (Hcasp3; CAC88866). In this analysis, Caenorhabditis elegans caspase Ced3 (AAG42045) was used as an outgroup. Only the region containing the highly conserved catalytic p20/p10 domains was used for alignment. The multiple sequence alignment was performed using the ClustalX program ver 1.83 with default parameters, and further edited manually for maximal homology. Phylogenetic analysis based on the above alignment was conducted by the Neighbor-Joining and Minimum Evolution methods of the MEGA program version 3.1 [16]. The confidence of the results was tested by performing 1000 bootstrap re-samplings of the data.

\subsection{Tissue distribution of $\mathrm{Pm}$ caspase mRNA}

Total RNAs were extracted from various tissues using TRIzol reagent (Invitrogen, USA). After treating with DNase I, total RNAs were primed with oligo-dT-anchor primer (Roche) and 
reverse-transcribed with SuperScript II (Invitrogen, USA) at $42{ }^{\circ} \mathrm{C}$ for $50 \mathrm{~min}$. Aliquots of this CDNA were then used for PCR analysis. The Pm caspase primer pair used for RT-PCR was P2198 (5'-CTGGAGTGCTGGTCCACTATACCT-3') and P2410 (5'-GGCAAGCTTATACTTTGGGGTAAAGTAAACCTTTC-3'). For internal control, an actin gene primer pair, $\mathrm{P} 1882$-actin $\mathrm{F} 1$ (5'-CCGTCATCAGGGTGTGATGGT-3') and P1883-actin R1 (5'-CCACGCTCAGTCATGATCTTCA-3'), was designed based on $P$. monodon actin 2 (AF100987).

\subsection{Construction of expression plasmids}

The full-length $P m$ caspase-coding region was cloned by RTPCR using pfu enzyme with the forward primer $5^{\prime}$ CCGAAGCTTACCATGGAGGAAACAGTCAACGGA-3' and reverse primer 5'-CGAGCGGCCGCCATACTTTGGGGTAAAGTAAACCTTTC-3', where the underlined nucleotides are HindIII and Notl cutting sites, respectively. The PCR products were digested with HindIII and Notl and cloned into pDHsp/FLAGHis, a Drosophila heat shock protein 70 promoter-based expression vector [13], to generate pDHsp-Pmcasp/FLAGHis, which expresses a FLAG-His6-tagged Pm caspase fusion protein. Expression plasmids encoding PmIAP, P35, and WSSV449 with C-terminal V5 tags were the same as those used by Leu et al. [13].

\subsection{Expression, purification, and enzymatic assay of Pm caspase from E. coli}

The DNA fragment containing the Pm caspase-coding region was amplified from the plasmid pDHsp-Pmcasp/ FLAG-His using pfu enzyme with the forward primer $5^{\prime}$-CTGCAACTACTGAAATCAACCAAG-3' and reverse primer $5^{\prime}$-GGCAAGCTTATACTTTGGGGTAAAGTAAACCTTTC-3', where the underlined nucleotides are a HindlII cutting site. The PCR product was restricted with $\mathrm{Ncol}$ and HindIII, and cloned into the $\mathrm{pET}-28 \mathrm{~b}(+)$. The resulting $\mathrm{pET}$ clone was transformed into BL21 Codon Plus E. coli cells (Stratagene). Recombinant Pm caspase protein was purified from the IPTG-induced bacterial culture using a HisPrep ${ }^{T M}$ FF $16 / 10$ column (Amersham Biosciences), and then desalted and concentrated through an Amicon Ultra-15 centrifugal filter device (Millipore). The purified recombinant protein was quantified using the Bradford method (BioRad) and stored at $-20^{\circ} \mathrm{C}$ in storage buffer (50 mM HEPES, pH 7.4, $100 \mathrm{mM} \mathrm{NaCl}, 0.5 \%$ CHAPS, $10 \mathrm{mM}$ DTT, $1 \mathrm{mM}$ EDTA, and $50 \%$ glycerol). The activity of the purified recombinant $\mathrm{Pm}$ caspase was measured using a Caspase-Glo 3/7 Assay kit (Promega) according to the manufacturer's instructions.

\subsection{Cell culture, transfections, and documentation of apoptotic responses in SF-9 cells}

S. frugiperda (Lepidoptera: Noctuidae) SF-9 insect cells were maintained at $27^{\circ} \mathrm{C}$ in Sf-900 II SFM medium (Invitrogen) supplemented with $10 \%$ heat-inactivated fetal bovine serum (Hyclone Laboratories). For transfection, SF-9 cells seeded in six-well plates $\left(0.5 \times 10^{6}\right.$ cells/well) were transfected with $3 \mu \mathrm{g}$ of the indicated plasmids using $3 \mu \mathrm{l}$ of Cellfectin Reagent (Invitrogen). After transfection for $16-18 \mathrm{~h}$, the cells were heat shocked in a $42^{\circ} \mathrm{C}$ water bath for $30 \mathrm{~min}$ and then returned to $27^{\circ} \mathrm{C}$. At $5-6 \mathrm{~h}$ after heat shock, the apoptotic responses in SF-9 cells were documented with photography.

\subsection{DNA ladder analysis}

Apoptotic DNA fragments were isolated according to the method published by Herrmann et al. [17]. Briefly, SF-9 cells in six-well plates $\left(1 \times 10^{6}\right.$ cells/well) were cotransfected with $2 \mu \mathrm{g}$ of pDHsp-Pmcasp/FLAG-His and with either $1 \mu \mathrm{g}$ of empty expression plasmid ( $\mathrm{pDH}$ sp/V5-His) or with expression plasmids encoding PmIAP, P35, or WSSV449. At the indicated times post heat shock, the cells and apoptotic bodies were pooled and suspended in lysis buffer containing $50 \mathrm{mM}$ Tris$\mathrm{HCl}$, pH 7.5, $20 \mathrm{mM}$ EDTA, and 1\% NP-40. After centrifugation for $5 \mathrm{~min}$ at $1600 \mathrm{~g}$, the supernatant was collected and the pellet was extracted again with lysis buffer. Both supernatants were pooled, brought to $1 \%$ SDS and to $5 \mu \mathrm{g} / \mu \mathrm{l}$ RNase $\mathrm{A}$, and incubated at $56{ }^{\circ} \mathrm{C}$ for $2 \mathrm{~h}$. Proteinase $\mathrm{K}$ was added to a final concentration of $2.5 \mu \mathrm{g} / \mu \mathrm{l}$ and incubation continued at $37^{\circ} \mathrm{C}$ for at least $2 \mathrm{~h}$. The ladder DNA was precipitated with $1 / 2 \mathrm{vol}$. of $10 \mathrm{M}$ ammonium acetate and $2.5 \mathrm{vol}$. of ethanol, then re-dissolved in gel loading buffer and analyzed by agarose gel electrophoresis.

\subsection{Western blot analysis}

SF-9 cells seeded in six-well plates $\left(1 \times 10^{6}\right.$ cells/well) were transfected and heat shocked to induce protein expression as described above. At the indicated times after heat shock, the cells were washed with phosphate-buffered saline (PBS; $137 \mathrm{mM} \mathrm{NaCl}, 10 \mathrm{mM}$ phosphate, $2.7 \mathrm{mM} \mathrm{KCl}, \mathrm{pH} 7.4$ ) and then lysed with SDS sample buffer. The proteins were separated using Tricine-SDS-polyacrylamide gel electrophoresis (PAGE) and transferred to Immobilon membranes (Millipore). Pm caspase was detected with mouse anti-FLAG antibody (1:5000; Sigma) and horseradish peroxidase-conjugated anti-mouse secondary antibody $(1: 10,000$; Santa Cruz). PmIAP, P35, and WSSV449 were detected with rabbit anti-V5 antibody (1:10,000; Sigma) and horseradish peroxidase-conjugated anti-rabbit secondary antibody (1:10,000; Santa Cruz). The proteins were visualized by a chemiluminescence reagent (Perkin-Elmer, Inc.).

\subsection{Co-immunoprecipitation}

SF-9 cells were seeded and cotransfected with the indicated plasmid DNAs as described in Section 2.7. At the indicated times after heat shock, the cells and apoptotic bodies were pooled, carefully washed with PBS, and then lyzed in NP-40 lysis buffer $(50 \mathrm{mM}$ Tris- $\mathrm{HCl}, \mathrm{pH} 8.0,150 \mathrm{mM} \mathrm{NaCl}, 1.0 \%$ Nonidet $\mathrm{P}$-40) supplemented with a protease inhibitor tablet (Roche). The lysates were centrifuged at $12,000 \mathrm{~g}$ for $5 \mathrm{~min}$ and the supernatants were then incubated with anti-FLAG M2 affinity gel (Sigma) at $4{ }^{\circ} \mathrm{C}$ overnight with rotation. After five extensive washes with NP-40 lysis buffer, the gel was dissolved in SDS sample buffer and the immunoprecipitaed proteins were separated by Tricine-SDS/12.5\% PAGE and further analyzed by Western blot. 


\subsection{Time-course study of Pm caspase and PmIAP RNAs in WSSV-infected shrimp by RT-PCR analysis}

Following the procedure described by Tsai et al. [18], several adult $P$. monodon were experimentally infected with WSSV by intramuscular injection (WSSV Taiwan isolate T1, Wang et al. [19]) and then collected at the indicated times post infection. Total RNAs were isolated from pleopods using TRIzol reagent (Invitrogen, USA), treated with DNasel (Roche), and then reverse-transcribed as described above. The Pm caspase primer pair used for RT-PCR was P2198/ P2410 (see Section 2.3). The PmIAP primers were 109F01R1 (5'-AGAAGAATAACGGCAAGTGACTG-3') and 109F01F1 (5'-GCCTCTTTAGGTCAAGTGTAG-3'). The wssv ie 1 primers were P1562 (5'-GACTCTACAAATCTCTTTGCCA-3') and P1500 (5'-CTACCTTTGCACCAATTGCTAG- $3^{\prime}$ ). The wsSV449 primers were P2667 (5'-GAGTTCCTGAAAGAGAGAGGA-3') and P1890 (5'-GCCGGATCCTACTCCACGCTGCTTGGA-3'). The P. monodon actin gene primers were as indicated above.

\subsection{Quantitative real-time RT-PCR assay}

P. monodon shrimps were experimentally infected with WSSV as described above, and at the indicated times post infection $(6,12,24$, and $36 \mathrm{hpi})$ three shrimps were randomly collected. Total RNAs were isolated from pleopods. The isolated RNAs $(1 \mu \mathrm{g})$ were treated with DNasel (Invitrogen, USA), and then reverse-transcribed using SuperScript II (Invitrogen, USA) at $42{ }^{\circ} \mathrm{C}$ for $50 \mathrm{~min}$. Aliquots of this CDNA were then used for quantitative real-time PCR analysis. The PmIAP primers used in this analysis were P2637 (5'-CAGCCACGTGAGTTCTGTTCA-3') and P2638 (5'-CGCTAAAGGAGAAATGACAGCA-3'), and the Pm caspase primers were P2530 (5'-CGTGGTTCATTCAGTCGCTG-3') and P2531 (5'-TCACGCTGGTCATCATGGAG- $3^{\prime}$ ). P. monodon EF- $1 \alpha$ (DQ021452) was used as a reference gene for internal standardization, and the corresponding primers were P2547 (5'-TGCTCTGGACAACATCGAGC-3') and P2548 (5'-CGGGCACTGTTCCAATACCT-3').

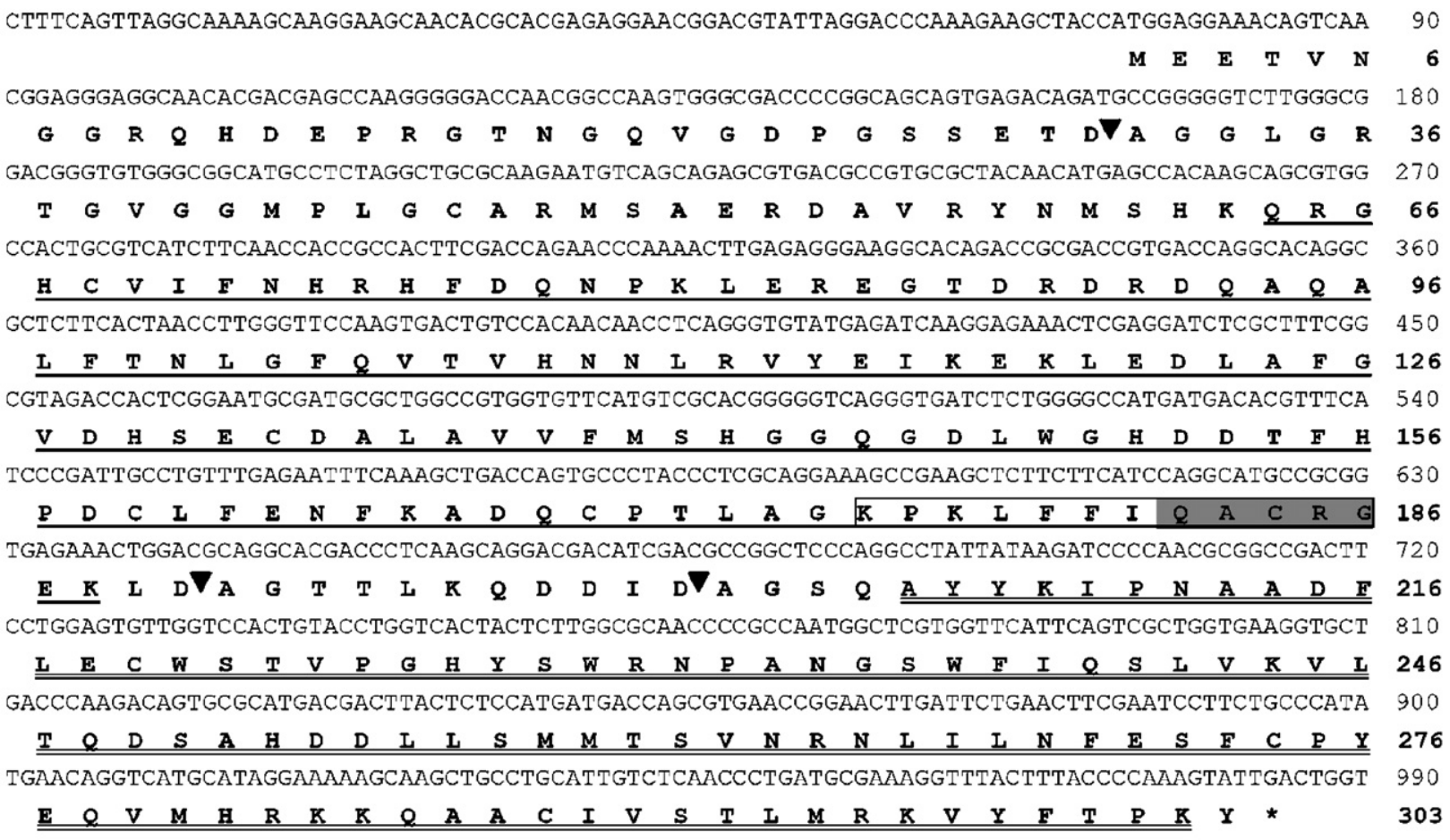

CCCCGAGCATAGGGAAGGAGGAGGCAGGTCTGACGCTATGCTCAGGGACGTAATAGAAGAGGCCCCAATAGCCAGAGCTGAGGAGGTGCA 1080

GGAACAAGAGCTGGGAGGTGCACTTGTGGCCCCCAATACCAGGAAGATGTYTATGATTAGTAATTCATATTAAGATTGGCCGGAGGAAG 1170

AGTAAGAGGAATGACAGAAGTTTTAGGATTAAAAAACGAAAACATGAAAGGTCCAAAACCATAAGTGAATAAAATCTTAAGGGAAAAGTG 1260

CCCAGCGATGAAGAATTCTCTTCGTGTAAAAATCGTCAGTGATICTTTTTATTCTTATGTTGGAATATTGTAAGTTGAAGCCCCATAAAT 1350

CTAGACCTACCATCAGAAAAAAAAAAAAAAAAA

1383

Fig. 1 Nucleotide and deduced amino acid sequences of Pm caspase. The nucleotide sequence is numbered from the first base at the $5^{\prime}$ end. The first methionine $(M)$ is numbered as the first deduced amino acid. Single underlining indicates the location of the caspase family p20 domain and double underlining shows the location of the caspase family p10 domain. The caspase family cysteine active site is boxed. The active site pentapeptide QACRG is shaded. Triangles indicate the putative internal cleavage sites, Asp 30, Asp 190, and Asp 201, of the Pm caspase. 
The qRT-PCR amplifications were carried out in duplicate for each sample in a total volume of $20 \mu \mathrm{l}$ containing $10 \mu \mathrm{l}$ SYBR Green $2 \times$ Supermix (Applied Biosystems, USA), $1 \mu \mathrm{l}$ of CDNA ( $1 \mathrm{ng}), 2 \mu \mathrm{l}$ of each primer $(3 \mu \mathrm{M})$, and $5 \mu$ water. The qRT-PCR program was $50^{\circ} \mathrm{C}$ for $2 \mathrm{~min}, 95^{\circ} \mathrm{C}$ for $10 \mathrm{~min}$, followed by 40 cycles of $95^{\circ} \mathrm{C}$ for $15 \mathrm{~s}$, and $60^{\circ} \mathrm{C}$ for $60 \mathrm{~s}$. A dissociation curve analysis $\left(95^{\circ} \mathrm{C}\right.$ for $15 \mathrm{~s}, 60^{\circ} \mathrm{C}$ for $30 \mathrm{~s}, 95^{\circ} \mathrm{C}$ for $15 \mathrm{~s}$ ) was included for each sample after PCR to check the specificity of the PCR products. The $C_{t}$ values for the IAP and caspase target genes and the $C_{\mathrm{t}}$ value for the internal control EF- $1 \alpha$ gene were determined for each sample. The expression levels of IAP and caspase in WSSV-infected shrimps relative to healthy shrimps were then determined using the $2^{-\triangle \Delta C T}$ method [20].

\section{Results}

\subsection{Identification and sequence analysis of $P$. monodon caspase}

The full-length sequence of $P$. monodon $(P m)$ caspase cDNA was deduced by subjecting hepatopancreas RNA from $P$. monodon to RT-PCR and 5'/3' RACE. As shown in Fig. 1, Pm caspase cDNA is $1386 \mathrm{bp}$, comprising a $5^{\prime}$ untranslated region (UTR) of $73 \mathrm{bp}$, an open reading frame (ORF) of $915 \mathrm{bp}$ and a $3^{\prime}$ UTR of $398 \mathrm{bp}$. The nucleotide and deduced amino acid sequences have been submitted to the NCBI database under the accession number EF114674. The Pm caspase ORF encodes a polypeptide consisting of 303 amino acids with a calculated molecular mass of $34.3 \mathrm{kDa}$. The AUG start codon of this ORF is located within a favorable context for translation [21]. ScanProsite analysis of the deduced amino acid sequence of $\mathrm{Pm}$ caspase revealed that the caspase family p20 domain is located at residues 64-189 (indicated by underlining in Fig. 1), the caspase family p10 domain spans residues 207-302 (indicated by double underlining) and the caspase family cysteine active site is at residues 176-189 (indicated by the box). The QACRG pentapeptide motif present in most caspases was also observed (residues 183-187, shaded area of the box).

BLASTP analysis of Pm caspase against the NCBI nr database revealed that $\mathrm{Pm}$ caspase was most similar to the insect effector caspases, including S. littoralis, S. frugiperda, $B$. mori, and D. melanogaster caspases, to which it exhibits approximately $41-44 \%$ identity and $57-62 \%$ similarity. Among the vertebrate caspases, Pm caspase was most similar to zebrafish and pig caspase- 3 with $42 \%$ identity and $58 \%$ similarity. Pairwise alignment of Pm caspase and Sf caspase1 revealed possible internal cleavage sites for generating the mature Pm caspase at Asp-30, Asp-190, and Asp-201 (Triangles in Fig. 1). This alignment also showed that Pm caspase has a short prodomain of 30 amino acids, and further suggested that Pm caspase is an effector caspase.

Molecular phylogenetic analysis was performed using the catalytic p20/p10 domains of effector caspases from

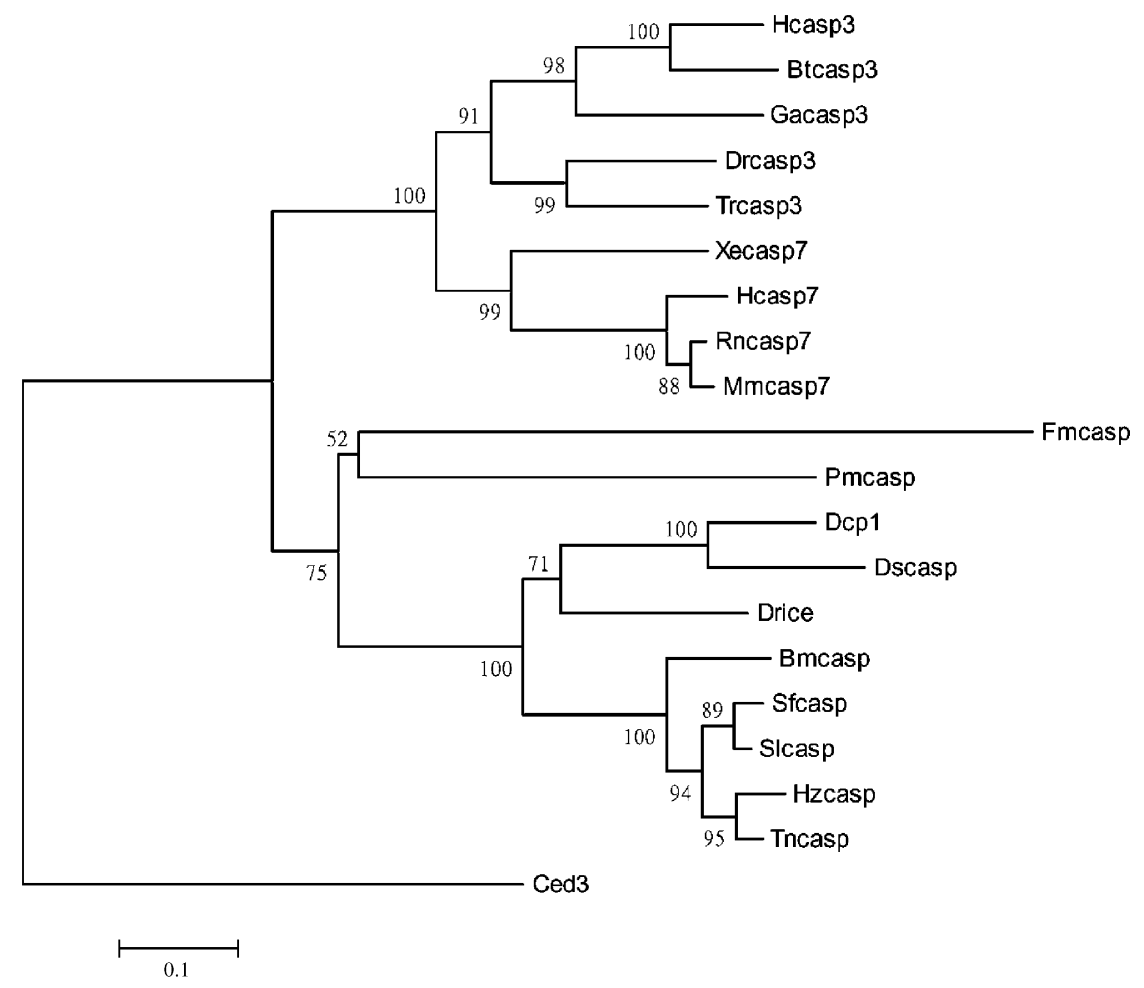

Fig. 2 Phylogenetic relationships among various effector caspases. A neighbor-joining distance tree comparing the p20 and p10 domains of these caspases is shown. The $C$. elegans Ced3 was used as an outgroup to root the tree. Bootstrap values are indicated. The scale represents number of substitutions per 100 amino acid residues. H, human; Bt, Bos taurus; Ga, Gallus gallus; Dr, Danio rerio; Tr, Takifugu rubripes; Xe, Xenopus tropicalis; Rn, Rattus norvegicus; Mm, Mus musculus; Fm, F. merguiensis; Pm, P. monodon; Ds, Drosophila pseudoobscura; Bm, Bombyx mori; Sf, Spodoptera frugiperda; Sl, Spodoptera littoralis; Hz, Helicoverpa armigera; Tn, Trichoplusia ni; Ced3, C. elegans caspase. Dcp1 and Drice are two Drosophila melanogaster caspases. 
shrimps, insects, and vertebrates. C. elegans caspase Ced3 was used here as an outgroup to root the tree. A distance tree constructed by the Neighbor-Joining method is shown in Fig. 2. The Minimum Evolution method produced similar results, but with different bootstrap values (data not shown). The caspases formed two clades, with the shrimp (Pmcasp and Fmcasp) and insect caspases in one clade, and all the vertebrate caspases in the other. This is consistent with the known evolutionary relationships among crustaceans, insects, and vertebrates.

\subsection{Tissue distribution of Pm caspase mRNA}

To investigate the expression pattern of Pm caspase transcripts, total RNAs were extracted from various $P$. monodon tissues and subjected to RT-PCR analysis.

Fig. 4 shows that $P m$ caspase transcripts were expressed in

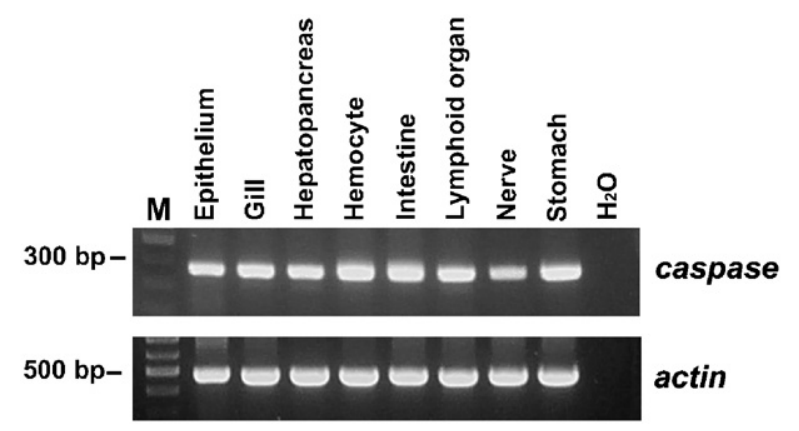

Fig. 3 Tissue distribution of $P m$ caspase mRNA by RT-PCR analysis. $\mathrm{H}_{2} \mathrm{O}$ was included as negative control. $M$ indicates molecular weight marker (100 bp ladder). all analyzed tissues, including epithelium, gill, hepatopancreas, hemocyte, intestine, lymphoid organ, nerve, and stomach (Fig. 3).

\subsection{Expression, purification, and enzymatic activity of Pm caspase}

To determine its caspase activity, full-length $\mathrm{Pm}$ caspase protein containing a C-terminal His6-tag was expressed in bacteria and purified. Our results showed that this protein was a soluble mature enzyme. As shown in Fig. 4A, the purified, mature Pm caspase migrated in Tricine-SDS-gel as four major bands of an apparent molecular mass of 21.0, $20.4,13.4$, and $11.7 \mathrm{kDa}$, respectively. Based on the predicted internal cleavage sites (Fig. 1), these protein bands should correspond to the regions defined by a.a. 31-201, 31-190, 191-303, and 202-303, respectively. The minor protein band (indicated by the asterisk) in Fig. 4A has an apparent molecular mass of $33.0 \mathrm{kDa}$ and might correspond to the prodomain-processed Pm caspase. To investigate the recombinant protein's caspase- 3 activity, four different amounts of protein, $1,0.5,0.1$, and $0.01 \mathrm{ng}$, were assayed. At $150 \mathrm{~min}$ after the addition of substrate reagent, the luminescence generated by $0.1-1 \mathrm{ng}$ of purified protein was between 10-100-fold higher than that from the bufferonly blank control (Fig. 4B). This result clearly showed that the purified $\mathrm{Pm}$ caspase was able to cleave the specific substrate for caspase-3/7, and thus supports the conclusion drawn from the amino acid sequence analysis that Pm caspase is an effector caspase.

These results also show that, just like many other caspases [22,23], when Pm caspase is overexpressed in
A

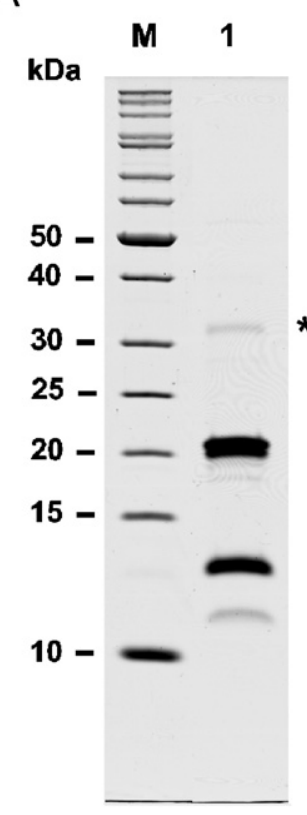

B

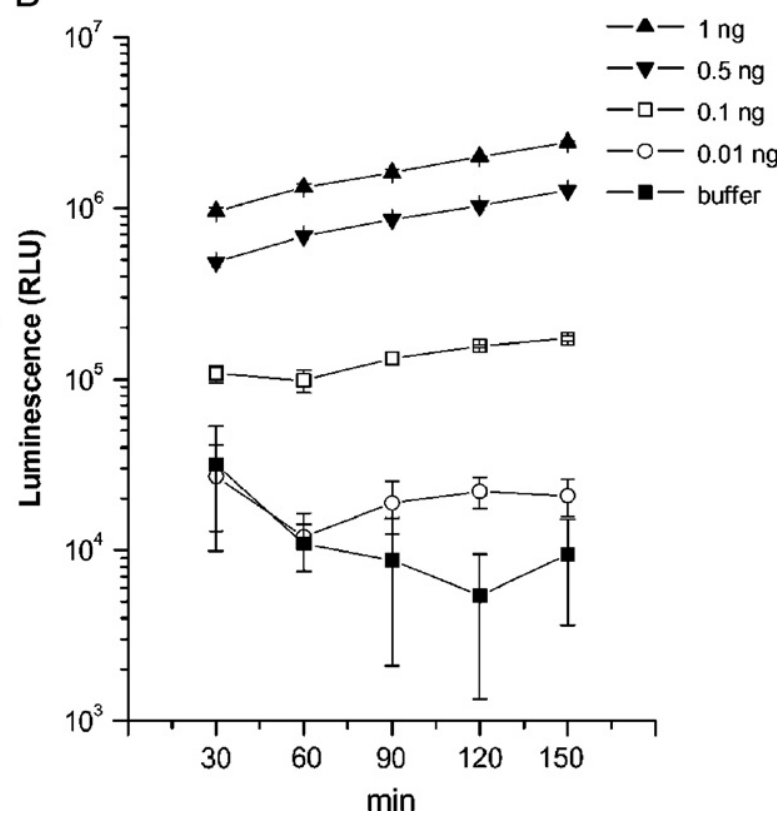

Fig. 4 Subunit profile and enzymatic activity of mature Pm caspase. (A) Pm caspase was expressed in E. coli, purified, and analyzed by Tricine-SDS-PAGE and Coomassie staining. Lane $\mathrm{M}$, molecular mass marker $(\mathrm{kDa})$; lane $1, \mathrm{Ni}^{2+}$-affinity purified mature Pm caspase. The asterisk indicates the minor protein band at $33 \mathrm{kDa}$. (B) Caspase-3 activity of four amounts of purified, mature Pm caspase. Following the addition of substrate reagent, luminescence was measured at the indicated times. The buffer used for protein dilution was also assayed and served as blank control. The results are the mean of three replicates. 
E. coli, it can autoprocess its internal cleavage sites (Fig. 4A) to generate subunits of mature, functionally active Pm caspase enzyme (Fig. 4B).

\subsection{Overexpression of Pm caspase induces apoptosis in SF-9 cells}

Several studies have demonstrated that many caspases induce apoptosis when overexpressed in cultured cells [24-26]. To investigate the pro-apoptotic activity of Pm caspase, we transiently transfected SF-9 cells with a FLAGtagged Pm caspase gene under the control of a Drosophila heat shock protein 70 promoter. At $16-18 \mathrm{~h}$ post transfection, the transfected cells were heat shocked to induce the expression of Pm caspase, and 5-6h later the morphological changes, including membrane blebbing and formation of apoptotic bodies, were observed (Fig. 5A). Western blot analysis with anti-FLAG antibody confirmed the expression of Pm caspase in the SF-9 cells (Fig. 5B). At $1 \mathrm{~h}$ post heat shock Pm caspase was detected as the full-length protein, while by $3 \mathrm{~h}$ post heat shock Pm caspase had been processed (Fig. 5B, lanes 2 and 3). Agarose gel analysis of DNAs isolated from transfected SF cells showed that the characteristic apoptotic DNA ladder could only be seen in cells expressing Pm caspase (Fig. 5C). Therefore, we concluded that both morphological and biochemical data confirmed the proapoptotic activity of Pm caspase.

\subsection{RNA levels of Pm caspase and Pm inhibitor of apoptosis protein (PmIAP) are relatively unchanged after WSSV infection}

WSSV infection induces apoptosis in shrimp [10,11]. To investigate whether WSSV infection modulates the gene expression levels of either Pm caspase or PmIAP, a time course study was conducted. At the indicated times post infection, total RNA was extracted from the pleopods of the experimental shrimp and then analyzed by RT-PCR using primer sets for caspase, IAP, actin, and wssv ie1 (Fig. 6A). Although the increased levels of wssv ie1 RNA confirmed that the shrimps were successfully infected with WSSV, RNA levels of both apoptosis-related genes remained relatively unchanged after WSSV infection (Fig. 6A). A quantitative real-time RT-PCR using different shrimp samples was used to reconfirm these results (Fig. 6B). As shown in Fig. 6B, after WSSV infection, the PmIAP mRNA levels remained approximately constant, and although $P m$ caspase mRNA levels were respectively lower and higher at 6 and $24 \mathrm{hpi}$, Student's $t$-test showed that neither fluctuation was statistically significant relative to the levels in healthy shrimp (0 hpi).

\subsection{The apoptosis induced by Pm caspase in SF-9 cells can be blocked by WSSV 449}

WSSV encodes an anti-apoptosis protein known as WSSV449 in the WSSV Taiwan strain (ORF390 in the WSSV China strain). This protein blocks the apoptosis induced in insect cells by infection with a p35-deficient baculovirus, and it therefore appears to function like the AcMNPV P35 protein
A
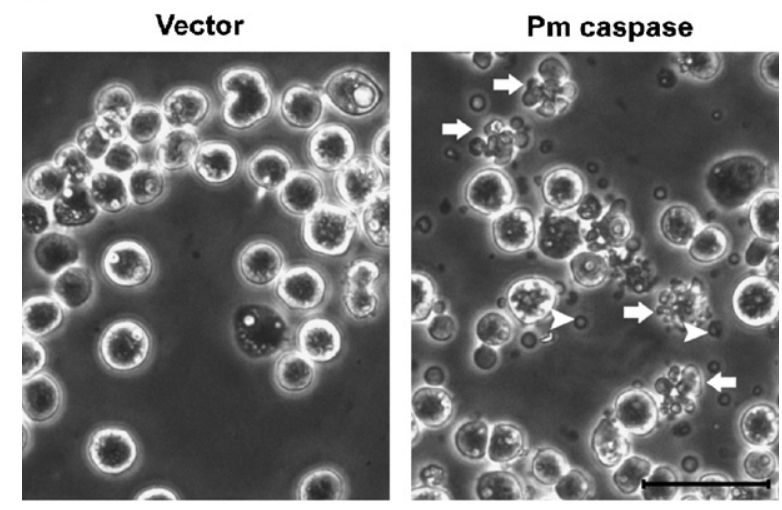

B

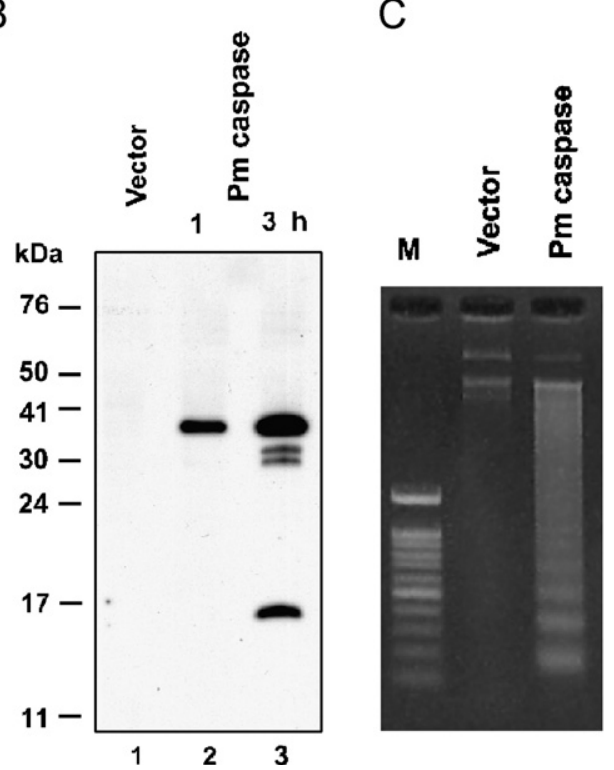

Fig. 5 Expression of $\mathrm{Pm}$ caspase in SF-9 cells induces apoptosis. The $\mathrm{Pm}$ caspase expression plasmid was transfected into SF-9 cells and heat-shocked to induce expression. (A) The expression of Pm caspase induced formation of apoptotic bodies in SF-9 cells. White arrows indicate apoptotic bodies, and white arrowheads indicate fragmented apoptotic bodies. Cells transfected with empty plasmid (Vector) containing no Pm caspase gene appeared normal. Scale bar $=25 \mu \mathrm{m}$. (B) At 1 and $3 \mathrm{~h}$ post heat shock (lanes 2 and 3, respectively), the cell lysates were harvested and subjected to Western blot analysis with antiFLAG antibody. Lysate from cells transfected with empty plasmid was used as negative control (lane 1). (C) At $16 \mathrm{~h}$ after heat shock, apoptotic DNA ladders were isolated from cells transfected with empty plasmid (Vector) or with Pm caspase, and separated on agarose gel. Lane $M, 100$ bp molecular weight marker.

[14]; however, the mechanism by which WSSV449 inhibits apoptosis has not been confirmed. P35 is a direct inhibitor of numerous caspases and, to investigate the possibility that WSSV449 might function as a caspase inhibitor, both Pm caspase and WSSV449 were coexpressed in SF-9 cells. In this study, PmIAP and P35 were also included for comparison.

After coexpression of the Pm caspase with the indicated proteins for $16-18 \mathrm{~h}$, the SF-9 cells were observed under the microscope. Both P35 and WSSV449 successfully inhibited 
A

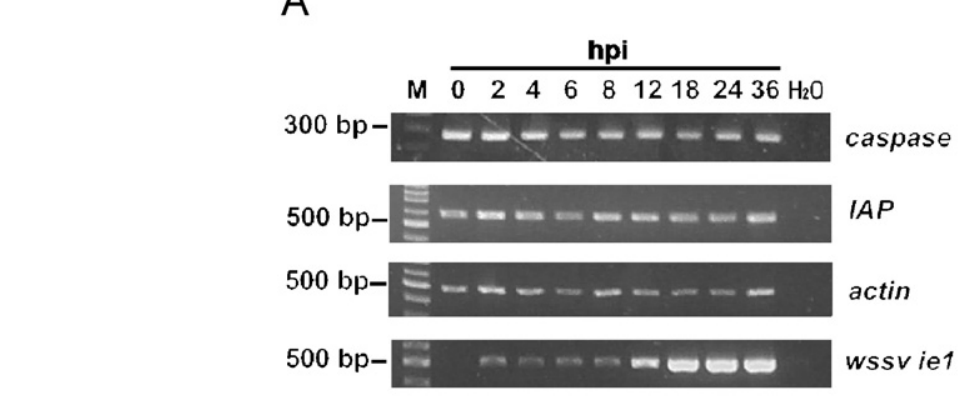

B
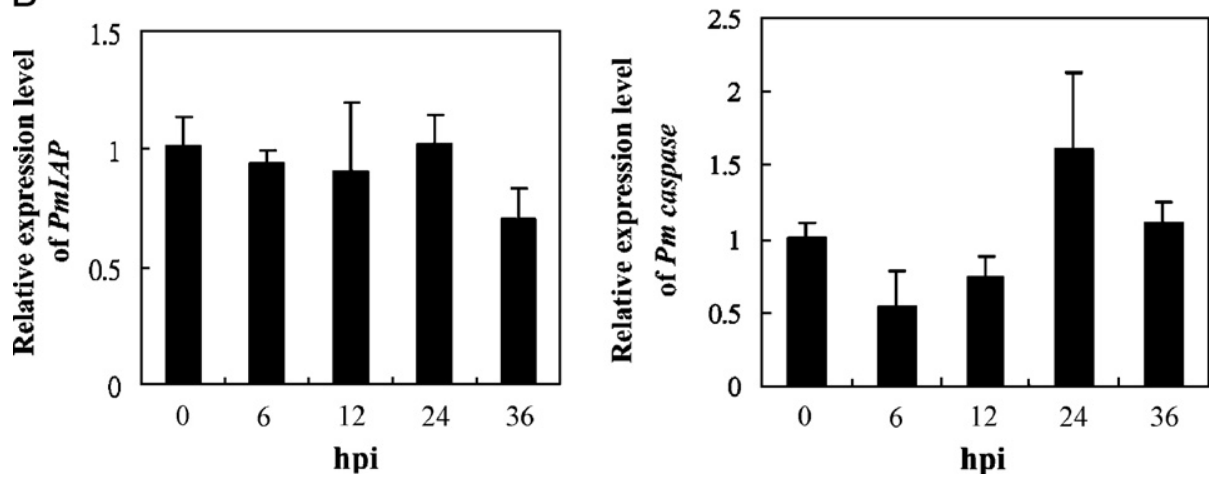

Fig. 6 Time course study of RNA levels of Pm caspase and PmIAP in pleopods after WSSV infection. (A) At the indicated times post infection, total RNAs were extracted from the pleopods and analyzed for the indicated genes by RT-PCR. The actin gene served as internal control and WSSV ie 1 was used to indicate the successful infection of the shrimp with WSSV. M indicates molecular weight marker (100 bp ladder). $\mathrm{H}_{2} \mathrm{O}$ was included as negative control. (B) Quantitative real-time PCR. Three WSSV-infected shrimps were randomly collected at the indicated times post infection. The expression levels of PmIAP and Pm caspase mRNA in WSSV-infected shrimps relative to that in healthy shrimp are shown as $2^{-\Delta \Delta C T}$ values.

the apoptotic effects induced by Pm caspase, but PmIAP was ineffective against Pm caspase-induced apoptosis (Fig. 7A). In a more quantitative, time course study (Fig. 7B), at $5 \mathrm{~h}$ post heat shock (left panel), the DNA ladder with the highest intensity was found in the SF-9 cells expressing Pm caspase only. At $16 \mathrm{~h}$ post heat shock, an almost equally high intensity DNA ladder was produced by the cells that coexpressed with PmIAP. Overall, these results suggest that both P35 and WSSV449 could completely block the proapoptotic activity of $\mathrm{Pm}$ caspase in SF-9 cells, whereas PmIAP showed only negligible anti-Pm caspase activity.

\subsection{Pm caspase cleaves WSSV449 and binds to the cleaved WSSV449}

To test whether Pm caspase is able to bind the three antiapoptosis proteins, PmIAP, P35 and WSSV449, Pm caspase was coexpressed in SF-9 cells with these proteins, and then cell extracts were analyzed by co-immunoprecipitation. Successful expression of these proteins was first checked with Western blot using anti-V5 antibody. When expressed alone, all three proteins expressed as single protein bands with molecular weights that conformed to previous studies [13] (Fig. 8A, left panel). However, when coexpressed together with $\mathrm{Pm}$ caspase (Fig. 8A, right panel), only the protein profile of PmIAP remained unchanged. The apparent molecular mass of P35 was reduced to about $25 \mathrm{kDa}$, while WSSV449 was detected as two protein bands: in addition to the full-length protein, a small protein of about $12 \mathrm{kDa}$ was identified. These results suggest that $\mathrm{Pm}$ caspase was able to cleave both P35 and WSSV449.

The cell lysates from coexpressed cells were then reacted with anti-FLAG resins to immunoprecipitate the FLAG-fused $\mathrm{Pm}$ caspase, and the immunoprecipitates were analyzed with Western blot using anti-V5 antibody. Fig. 8B (upper panel) shows that the three anti-apoptosis proteins could all bind to Pm caspase. For WSSV449, although both the intact and cleaved proteins were present in the input cell lysate (Fig. 8A, right panel), only the cleaved protein was coimmunoprecipitated by the anti-FLAG resin, suggesting that Pm caspase interacted only with the cleaved WSSV449, and not with the full-length protein. The immunoprecipitates were also analyzed with Western blot using anti-FLAG antibody to ensure that Pm caspase was precipitated (lower panel).

\section{Discussion}

Several mammalian, insect, and hydra caspases have already been successfully cloned using degenerate PCR primers $[15,27,28]$, and in the present study this strategy was used to clone the caspase gene from $P$. monodon. From our results (Figs. 1 and $4 \mathrm{~B}$ ), we conclude that the $P m$ caspase cloned in this study is an effector caspase. We also found that the novel anti-apoptosis protein WSSV449 encoded by WSSV is a caspase inhibitor (Figs. 7 and 8).

Model species are known to have several caspases. For example, Drosophila has seven: three are initiators with 
A

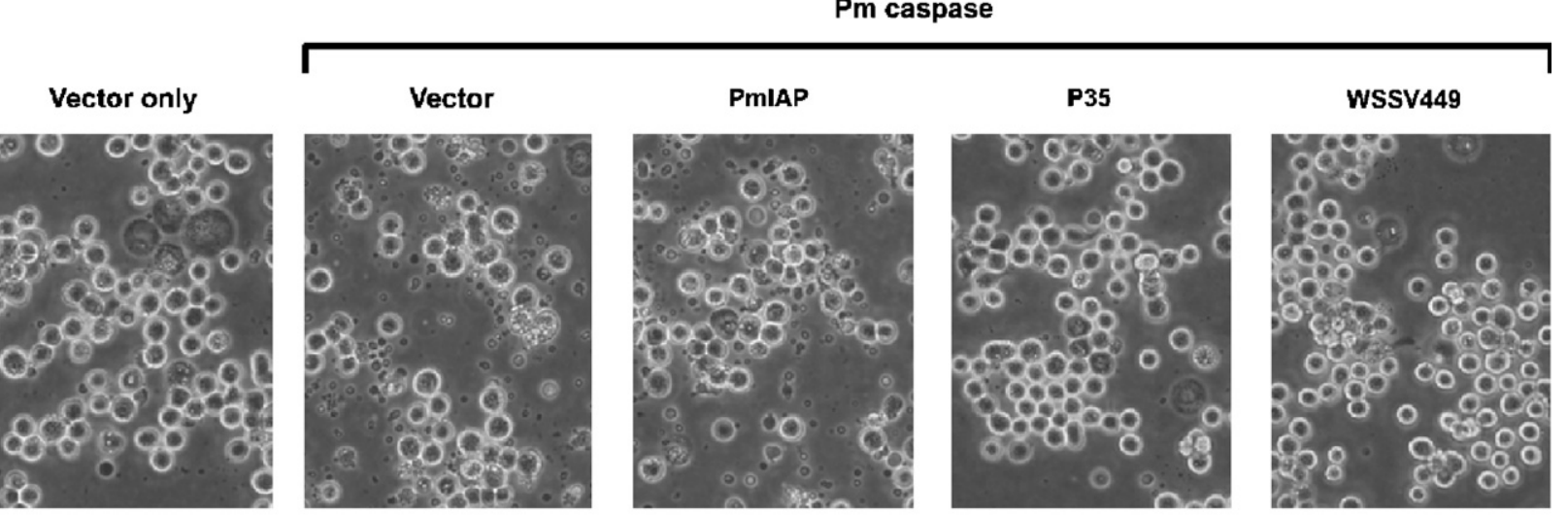

B

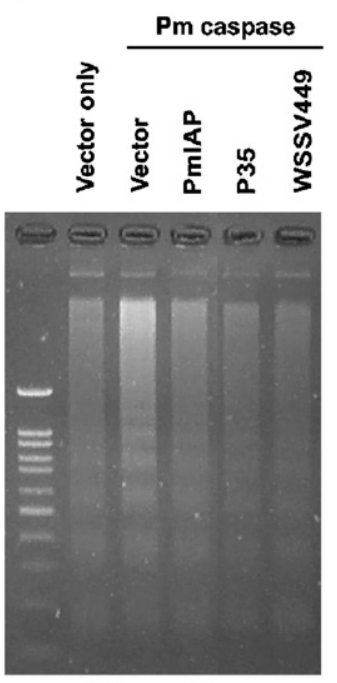

$5 \mathrm{~h}$ post h.s.
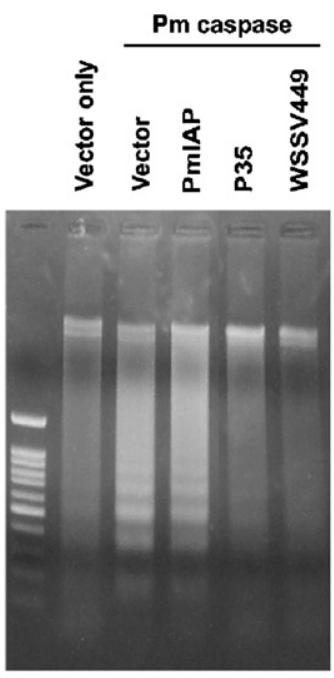

$16 \mathrm{~h}$ post h.s.

Fig. 7 Apoptosis in SF-9 cells induced by Pm caspase is completely blocked by WSSV449, but only partially blocked by PmIAP. A plasmid encoding Pm caspase was cotransfected into SF-9 cells either with a plasmid encoding PmIAP, P35 or WSSV449, or with an empty expression plasmid (Vector). SF-9 cells transfected only with the empty expression plasmid were included as negative control (Vector only). (A) Micrographs of the cells at 16-18 h after heat shock. (B) Agarose gel analysis of DNA ladders produced by the transfected cells at $5 \mathrm{~h}$ post heat shock (left panel) or at $16 \mathrm{~h}$ post heat shock (right panel). $M$ indicates molecular weight marker (100 bp ladder).

long prodomains, and four are effector caspases with short prodomains. Humans also have several kinds of both initiator and effector caspases. It is therefore reasonable to expect shrimps to also have several caspases, and in support of this a comparison of the two effector caspases, $\mathrm{Pm}$ caspase and Fm caspase, shows only $32 \%$ identity and $47 \%$ similarity in their full-length amino acid sequences, which suggests that they are not orthologous. In fact, the expected Fm caspase orthologue has been identified very recently in $P$. monodon (ABI34434) [29]: full-length amino acid sequences are $82 \%$ identical and $90 \%$ similar. In addition to these effector caspases, a shrimp initiator caspase has also been found in Marsupenaeus japonicus (ABK62771). These findings raise several related and interesting questions in terms of WSSVinduced apoptosis response in shrimps. For example, does WSSV infection activate all the different caspases equally or will a differential response be elicited? Further, does the WSSV anti-apoptosis protein, WSSV449, inhibit all these caspases equally or differentially? All these questions will need to be investigated in future studies.

WSSV infection induces apoptosis in shrimp, and early studies have shown that apoptotic responses mainly occur in non-infected, bystander cells, whereas WSSV-infected cells are non-apoptotic [11]. Although we still do not know the mechanisms by which WSSV triggers apoptosis in noninfected cells, our present data now shows that it cannot be by modulating the expression of Pm caspase or PmIAP (Fig. 6). Conversely, the anti-apoptotic activity of WSSV is at least partially known. WSSV449 (ORF390) is an antiapoptosis protein encoded by WSSV [14]; our present data show that it functions by directly binding to and inhibiting Pm caspase, and, further, that only cleaved WSSV449 can bind to Pm caspase (Fig. 8). In these respects, WSSV449 is functionally similar to baculovirus P35 and we therefore hypothesized that these two anti-apoptosis proteins might use similar mechanisms. P35 is a broad-spectrum 
A

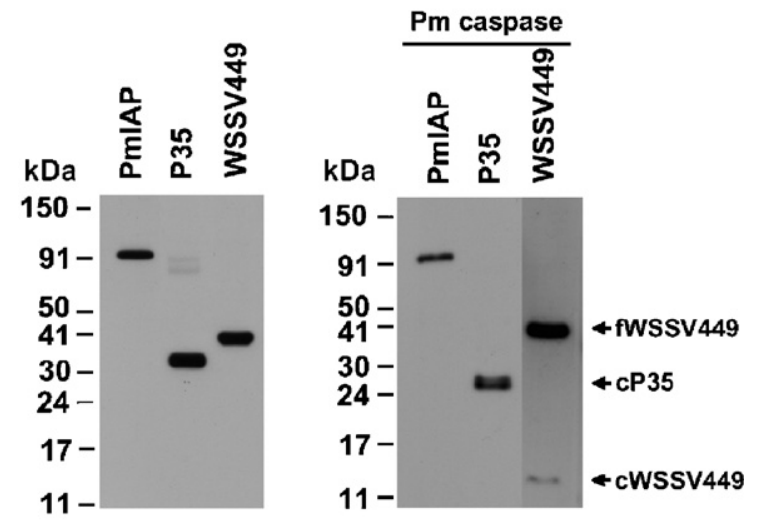

B

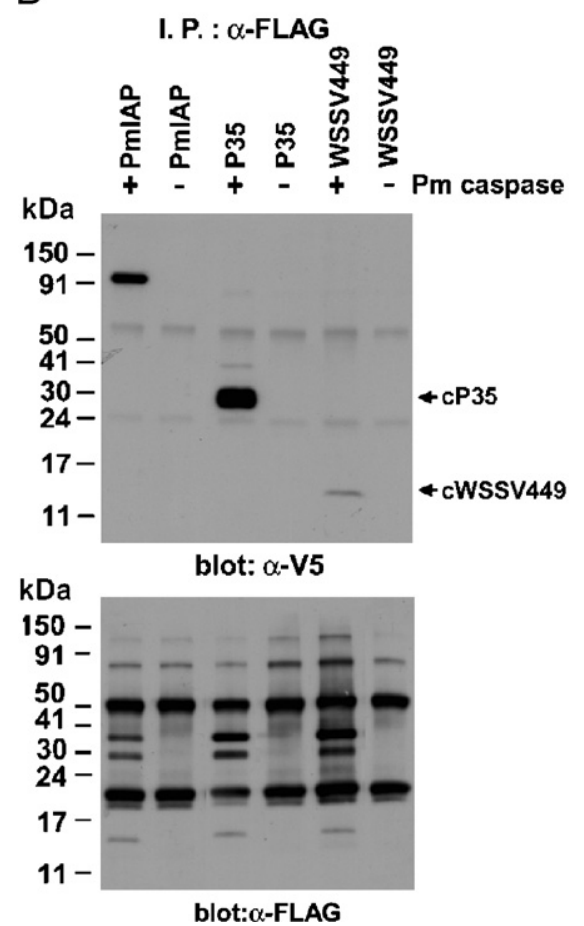

Fig. 8 Pm caspase binds to and cleaves WSSV449. (A) Expression of PmIAP, P35 and WSSV449 in SF-9 cells in the presence (right panel) or absence (left panel) of coexpressed $\mathrm{Pm}$ caspase. The cell lysates were harvested at $16 \mathrm{~h}$ after heat shock and subjected to Western blot analysis with anti-V5 antibody. The positions of full-length WSSV449 (fWSSV449), cleaved WSSV449 (cWSSV449) and cleaved P35 (cP35) in the right panel are indicated. (B) The above lysates were subjected to immunoprecipitation with anti-FLAG resin. The immunoprecipitates were analyzed with Western blotting using anti-V5 antibody to detect the three anti-apoptosis proteins (upper panel) or using anti-FLAG antibody to detect Pm caspase (lower panel). The specificity of anti-FLAG resin for immunoprecipitation was confirmed by using the cell lysates from SF-9 cells expressing only PmIAP, P35 or WSSV449. The positions of cleaved P35 (CP35) and cleaved WSSV449 (cWSSV449) are indicated.

anti-caspase inhibitor that has a caspase cleavage site DQMD at amino acids 84-87. The cleavage of this site by the target caspase generates the 10 and $25 \mathrm{kDa}$ cleavage products of
P35, both of which are stably associated with the inhibited caspase. The formation of this stoichiometric complex between P35 and the target caspase prevents subsequent access to the target caspase by any other substrate [30,31]. Like P35, WSSV449 also has a predicted caspase-3 cleavage site DEVDG at amino acids 269-273. In the presence of Pm caspase, a cleaved WSSV449 protein of about $12 \mathrm{kDa}$ was detected with the anti-V5 antibody (Fig. 8A, right panel), which is in accordance with the predicted C-terminal caspase- 3 cleaved product size of $11.6 \mathrm{kDa}$. Co-immunoprecipitation then showed that only the cleaved WSSV449 bound to the Pm caspase (Fig. $8 \mathrm{~B}$ ). So far, all of these data support our hypothesis that WSSV449 uses a mechanism similar to that used by P35, but further study will be needed to determine whether WSSV449 is also a broad-spectrum caspase inhibitor.

In the present study, we found that PmIAP only minimally inhibits the activity of Pm caspase, and that even though PmIAP binds to Pm caspase extensive apoptosis still occurs in SF-9 cells (Figs. 7 and 8). PmIAP is not the only member of the IAP family that binds to a caspase without producing any appreciable reduction in the caspase's activity. For example, in contrast to human X-chromosome-linked IAP (XIAP), which is a strong binding inhibitor of the effector and initiator caspases, both human cellular IAP-1 (c-IAP1) and c-IAP2 are extremely weak binding inhibitors and the bound caspases remain catalytically active [32]. In mammals, XIAP may be the only IAP that has the capacity to inhibit caspase under natural physiological conditions, while the question of whether other IAPs also function as caspase inhibitors remains controversial [32]. Drosophila IAP1 (DIAP1) also shows no inhibitory activity toward bound caspases [33], but alone among the noninhibitory binding IAPs, the mechanism for its anti-caspase activity is relatively well understood, and a "co-degradation model" has been proposed [34]. This model postulates a powerful mechanism to completely and absolutely block caspase activity by proteasome-dependent degradation of the DIAP1-caspase complex. However, this co-degradation model depends on the instability of DIAP1, whereas in SF cells we have shown that PmIAP is in fact very stable in the presence of $\mathrm{Pm}$ caspase (Fig. 8A). We therefore concluded that the "codegradation" strategy is evidently not being used by PmIAP to down-regulate Pm caspase in SF cells. Nevertheless, the importance of non-caspase inhibiting IAPs in controlling apoptosis is generally accepted, and it is unfortunate that there is no other evidence to suggest how PmIAP is causing this inhibition. For the present, the precise mechanism of how PmIAP inhibits apoptosis remains unknown.

\section{Acknowledgments}

This investigation was supported financially by the National Science Council grants (NSC96-2317-B-002-005, NSC95-2317B-002-009 and NSC95-2317-B-002-010). Both Guang-Hsiung Kou and Chu-Fang Lo are corresponding authors for this work. We are indebted to Paul Barlow for his helpful criticism.

\section{References}

[1] Jacobson MD, Weil M, Raff MC. Programmed cell death in animal development. Cell 1997;88:347-54. 
[2] Kerr JFF, Wylie AH, Currie AR. Apoptosis: a basic biological phenomenon with wide-ranging implications in tissue kinetics. Br J Cancer 1972;26:239-57.

[3] Danial NN, Korsmeyer SJ. Cell death: critical control points. Cell 2004;116:205-19.

[4] Shi Y. Caspase activation, inhibition, and reactivation: a mechanistic view. Protein Sci 2004;13:1979-87.

[5] Adams JM, Cory S. Apoptosomes: engines for caspase activation. Curr Opin Cell Biol 2002;14:715-20.

[6] Riedl SJ, Shi Y. Molecular mechanisms of caspase regulation during apoptosis. Nat Rev Mol Cell Biol 2004;5:897-907.

[7] Everett $\mathrm{H}, \mathrm{McF}$ adden $\mathrm{G}$. Apoptosis: an innate immune response to virus infection. Trends Microbiol 1999;7:160-5.

[8] Koyama AH, Fukumoria T, Fujitaa $M$, Irieb $H$, Adachi A. Physiological significance of apoptosis in animal virus infection. Microbes Infect 2000;2:1111-7.

[9] Khanobdee K, Soowannayan C, Flegel TW, Ubol S, Withyachumnarnkul B. Evidence for apoptosis correlated with mortality in the giant black tiger shrimp Penaeus monodon infected with yellow head virus. Dis Aquat Org 2002;48: 79-90.

[10] Sahtout AH, Hassan MD, Shariff M. DNA fragmentation, an indicator of apoptosis, in cultured black tiger shrimp Penaeus monodon infected with white spot syndrome virus (WSSV). Dis Aquat Org 2001;44:155-9.

[11] Wongprasert K, Khanobdee K, Glunukarn SS, Meeratana P, Withyachumnarnkul B. Time-course and levels of apoptosis in various tissues of black tiger shrimp Penaeus monodon infected with white-spot syndrome virus. Dis Aquat Org 2003;20(55): 3-10.

[12] Phongdara A, Wanna W, Chotigeat W. Molecular cloning and expression of caspase from white shrimp Penaeus merguiensis. Aquaculture 2006;252:114-20.

[13]. Leu JH, Kuo YC, Kuo GH, Lo CF. Molecular cloning and characterization of an inhibitor of apoptosis protein (IAP) from the tiger shrimp, Penaeus monodon. Dev Comp Immunol (2007), doi:10.1016/j.dci.2007.05.005.

[14] Wang Z, Hu L, Yi G, Xu H, Qi Y, Yao L. ORF390 of white spot syndrome virus genome is identified as a novel anti-apoptosis gene. Biochem Biophys Res Commun 2004;325:899-907.

[15] Pei Z, Reske G, Huang Q, Hammock BD, Qi Y, Chejanovsky N. Characterization of the apoptosis suppressor protein P49 from the Spodoptera littoralis nucleopolyhedrovirus. J Biol Chem 2002;277:48677-84.

[16] Kumar S, Tamura K, Nei M. MEGA3: integrated software for Molecular Evolutionary Genetics Analysis and sequence alignment. Brief Bioinform 2004;5:150-63.

[17] Herrmann M, Lorenz HM, Voll R, Grunke M, Woith W, Kalden JR. A rapid and simple method for the isolation of apoptotic DNA fragments. Nucleic Acids Res 1994;22:5506-7.

[18] Tsai MF, Kou GH, Liu HC, Liu KF, Chang CF, Peng SE, et al. Longterm presence of white spot syndrome virus (WSSV) in a cultured shrimp population without disease outbreaks. Dis Aquat Org 1999;38:107-14.

[19] Wang CH, Lo CF, Leu JH, Chou CM, Yeh PY, Chou HY, et al. Purification and genomic analysis of baculovirus associated with white spot syndrome (WSBV) of Panaeus monodon. Dis Aquat Org 1995;23:239-42.

[20] Livak KJ, Schmittgen TD. Analysis of relative gene expression data using real-time quantitative PCR and the $2^{-\Delta \Delta C T}$ method. Methods 2001;25:402-8.

[21] Kozak M. Interpreting cDNA sequences: some insights from studies on translation. Mamm Genomes 1996;7:563-74.

[22] Ahmad M, Srinivasula SM, Wang L, Litwack G, FernandesAlnemri T, Alnemri ES. Spodoptera frugiperda caspase-1, a novel insect death protease that cleaves the nuclear immunophilin FKBP46, is the target of the baculovirus antiapoptotic protein P35. J Biol Chem 1997;272:1421-4.

[23] Fraser AG, Evan GI. Identification of a Drosophila melanogaster ICE/CED-3-related protease, drICE. EMBO J 1997;16:2805-13.

[24] Dorstyn L, Colussi PA, Quinn LM, Richardson H, Kumar S. DRONC, an ecdysone-inducible Drosophila caspase. Proc Natl Acad Sci USA 1999;96:4307-12.

[25] Dorstyn L, Read SH, Quinn LM, Richardson H, Kumar S. DECAY, a novel Drosophila caspase related to mammalian caspase- 3 and caspase-7. J Biol Chem 1999;274:30778-83.

[26] Doumanis J, Quinn L, Richardson H, Kumar S. STRICA, a novel Drosophila melanogaster caspase with an unusual serine/ threonine-rich prodomain, interacts with DIAP1 and DIAP2. Cell Death Differ 2001;8:387-94.

[27] Alnemri ES. Mammalian cell death proteases: a family of highly conserved aspartate specific cysteine proteases. J Cell Biochem 1997;64:33-42.

[28] Cikala M, Wilm B, Hobmayer E, Bottger A, David CN. Identification of caspases and apoptosis in the simple metazoan Hydra. Curr Biol 1999;9:959-62.

[29] Wongprasert K, Sangsuriya P, Phongdara A, Senapin S. Cloning and characterization of a caspase gene from black tiger shrimp (Penaeus monodon)-infected with white spot syndrome virus (WSSV). J Biotechnol 2007;131:9-19.

[30] Bump NJ, Hackett M, Hugunin M, Seshagiri S, Brady K, Chen P, et al. Inhibition of ICE family proteases by baculovirus antiapoptotic protein p35. Science 1995;269:1885-8.

[31] Fisher AJ, Cruz W, Zoog SJ, Schneider CL, Friesen PD. Crystal structure of baculovirus $\mathrm{P} 35$ : role of a novel reactive site loop in apoptotic caspase inhibition. EMBO J 1999;18:2031-9.

[32] Eckelman BP, Salvesen SG. The human anti-apoptotic proteins CIAP1 and CIAP2 bind but do not inhibit caspases. J Biol Chem 2006;281:3254-60.

[33] Tenev T, Zachariou A, Wilson R, Ditzel M, Meier P. IAPs are functionally non-equivalent and regulate effector caspases through distinct mechanisms. Nat Cell Biol 2005;7:70-7.

[34] Ditzel M, Meier P. Ubiquitylation in apoptosis: DIAP1's (N-)en(d)igma. Cell Death Differ 2005;12:1208-12. 